Thélème. Revista Complutense de Estudios Franceses ISSN-e: 1989-8193

http://dx.doi.org/10.5209/THEL.52432

\title{
Shakespeare en Diderot: una crítica del gusto neoclásico
}

\author{
Nicolás Martín Olszevicki*
}

Recibido: 22/04/2016 / Aceptado: 27/02/17

Resumen. La recepción de la obra de Shakespeare en Francia en el siglo XVIII fue dificultosa debido a la influencia conjunta del neoclasicismo, el concepto aristocrático de "bon goût" y las críticas de Voltaire. En este artículo, no obstante, luego de reconstruir la confluencia de estos tres factores íntimamente relacionados entre sí, trazamos un recorrido por la obra de Denis Diderot, entre la Lettre sur les sourds et muets y los Salones, para demostrar que la figura del bardo inglés, lejos de ser de importancia lateral, tiene una función central en su pensamiento estético. La reformulación diderotiana de la lógica teatral bajo un paradigma a la vez pictórico y pantomímico a partir de 1757 se encuentra condensada en un momento particular de la obra shakesperiana, que se convierte así en un exemplum del modo en que el drama debe funcionar cuando las reglas y el decoro comienzan a convertirse en obstáculos para cumplir con el doble objetivo de deleitar y educar al público.

Palabras clave: Shakespeare, Macbeth, Diderot, Teatro, Gusto.

\section{Shakespeare in Diderot: a critic of neoclassical taste}

Abstract. The reception of Shakespeare's plays in France was difficult because of the combined influence of neoclassicism, Voltaire's writings and the aristocratic concept of "bon goût". Nevertheless, in this article, after reconstructing the confluence of this three factors, we analyze several works by Denis Diderot, from the Lettre sur les sourds et muets to the Salons, in order to show that the influence of the "Bard of Stratford" is central to his aesthetic thinking. His reformulation of the theatrical logic under a pictorial and pantomimic paradigm, from 1757 onwards, finds a condensed example in a particular moment of a Shakespearean play. That moment becomes an exemplum of how the drama should work when rules and decorum become obstacles in the way to achieve the double objective of delighting and educating the public.

Keywords: Shakespeare, Macbeth, Diderot,Theatre,Taste.

\section{Shakespeare dans Diderot : une critique du goût néoclassique}

Résumé. La réception de Shakespeare en France au XVIIIe siècle a été difficile en raison de l'influence combinée du néoclassicisme, les écrits de Voltaire et le concept aristocratique du «bon goût ». Cependant, dans cet article, après de reconstruire la confluence de ces trois facteurs, nous parcourons quelques œuvres de Denis Diderot, de la Lettre sur les sourds et les muets jusqu'aux Salons, pour montrer que la figure du barde anglais a un rôle central dans sa pensée esthétique. La reformulation diderotienne de la logique théâtrale sous un paradigme pictural et pantomimique trouve un point de condensation dans un moment particulier de l'œuvre shakespearienne, qui devient un exemplum de la façon

* Universidad de Buenos Aires / Université Paris IV-Sorbonne / CONICET.

nolsze@gmail.com 
dont le drame doit travailler lorsque les règles et le décorum deviennent des obstacles pour le double objectif de plaire et instruire le public.

Mots clés: Shakespeare, Macbeth, Diderot, Théâtre, Goût.

Sumario. Lo sublime, lo pictórico y la absorción en la teoría dramática de Diderot.

Cómo citar: Olszevicki, N. M. (2017). "Shakespeare en Diderot: una crítica del gusto neoclásico". Thélème. Revista Complutense de Estudios Franceses, 32(1), 71-84.

En un interesante artículo sobre las disputas por el canon literario durante la Ilustración europea, el crítico Howard Weinbrot apunta que, históricamente, las relaciones anglo-francesas podrían caracterizarse como un "matrimonio sellado en el infierno":

De un lado no se olvidaba la invasión normanda; del otro no se olvidaban Agincourt, Cressy y Poitiers. Una se percibía a sí misma como una inimitable nación libre; la otra se percibía a sí misma como una nación polite universalmente imitada. En su mayor parte, la esencial respuesta francesa a lo inglés en el siglo XVII y comienzos del XVIII fue una alegremente alimentada ignorancia (Weinbrot, 1993: 79) ${ }^{1}$.

No resulta sorprendente, por lo tanto, que el camino hacia la aceptación de la obra de William Shakespeare en Francia, que, aunque con algunos antecedentes ${ }^{2}$, se consolidaría fuertemente recién en la segunda mitad del siglo XVIII, haya sido largo y trabajoso. Incómoda heredera de la política cultural de la era de Louis XIV, la Francia ilustrada tuvo que derribar diversos y muy arraigados prejuicios estéticos nacionales para poder adoptar la dramaturgia del bardo inglés, consagrada parcialmente recién a partir de la insoslayable traducción de Letourneur ${ }^{3}$ de sus obras completas desde 1776 y definitivamente instalada en el canon gracias a los trabajos reivindicatorios de los escritores del siglo XIX (el panfleto Racine et Shakespeare [1823-25], de Stendhal, y el Préface de Cromwell [1827] y el William Shakespeare [1864] de Victor Hugo, son, sin dudas, los textos más importantes y conocidos) y la visita de una compañía inglesa en 1827 y 1828 que, aunque no de primera calidad, constituyó un "evento cardinal"

1 Las traducciones, en todos los casos en que no se indique lo contrario, son nuestras.

2 Uno de los hechos que marcan, antes de la publicación de las Lettres philosophiques voltaireanas (1734), el cambio de época que implicó el siglo XVIII en la asimilación francesa de las producciones culturales provenientes del otro lado del Canal de la Mancha, fue la aparición, en 1717, de un periódico cuyo fin específico era dar a conocer las obras literarias insulares al público galo: la Bibliothèque ou Histoire Littéraire de la Grand Bretagne. Otro hito en este proceso fue la publicación del periódico Le pour et le contre, editado por Prévost (acaso el primer anglómano convencido) a partir de 1733, en el que se proponía insertar en cada número curiosidades sobre Inglaterra y sus progresos en las ciencias y en las artes. Ya en 1731, en sus Mémoires et aventures d'un homme de qualité, Prévost había dedicado un volumen a un Séjour en Angleterre que incluía visitas al teatro y sugería una reevaluación de los estándares de gusto franceses. Allí, el portavoz del autor llegaba a comparar lo mejor del teatro británico con las obras maestras de Grecia y de su propia nación. Para una reconstrucción exhaustiva de la recepción de la cultura inglesa en la Francia del Ancien Régime, véase el todavía provechoso (aunque ya algo antiguo) trabajo de Jusserand (1899) y el más reciente, aunque menos exhaustivo, de Pemble (2005). En este artículo, nos concentraremos sólo en los puntos que consideramos centrales para comprender los alcances e identificar los oponentes retóricos de la operación teórica diderotiana.

3 No casualmente, Letourneur fue también el traductor de las Conjectures on original composition de Edward Young, una de las obras clave del surgimiento de la estética del genio en el siglo XVIII europeo. 
en los anales de la École Romantique (Pemble, 2005: 8).

Esta demora en la recepción shakespeariana en el Siglo de las Luces ha sido explicada recurriendo a diversos factores, como es esperable en toda reconstrucción rigurosa de un proceso complejo de traspaso y apropiación cultural. Son tres, estrechamente relacionados entre sí, los motivos que sobresalen como los más relevantes: en primer lugar, la persistente influencia de la estética clásica impuesta desde el reinado de Luis XIII a través de la Académie fundada por Richelieu (1635), cuyos principios fundamentales, como se sabe, eran el respeto de la separación entre los grandes géneros (Comedia y Tragedia), las unidades dramáticas (de tiempo, de lugar y de acción) y el decoro; en segundo lugar, la consolidación del inestable concepto de bon goût en el ámbito aristocrático; por último, la dilatada dispersión de las opiniones del philosophe más influyente de la época, Voltaire, quien desde sus Lettres philosophiques (1734) hasta su Lettre à l'Académie (1776) intentó predicar, aunque como veremos de manera un tanto ambigua, los perniciosos efectos que podía tener la difusión de la obra del bardo inglés para la escena estética y el proceso civilizatorio de la Francia posterior a Luis $\mathrm{XIV}^{4}$.

Reconstruir los principios regulativos y valorativos de la estética clásica, enunciados de la manera más sistemática en el Art poétique de Nicolás Boileau-Déspreaux (1674), resulta, para los límites de este trabajo, imposible. Baste señalar que los ideales de mesura, refinamiento del lenguaje, equilibrio y bienséance serán interrogados y puestos en crisis uno a uno en la reforma dramática propuesta por Denis Diderot. Estos ideales confluyen, por su parte, en la idea de bon goût, cuya plasticidad acarrea complejas dificultades cuando se intenta definirla de manera precisa. Según el importante estudio de Dens (1981), el concepto, importado originalmente de la obra de Gracián y Castiglione, tomó forma en el ámbito aristocrático francés del siglo XVII como un arma de combate intelectual, y fue el confuso producto de una negociación entre el espíritu cartesiano racional, por un lado, y el rechazo del estricto dogmatismo de las reglas académicas, por el otro, que representaba a un estado opresor que pretendía fijar pautas para una nobleza que, con las insurrecciones de la Fronda, había demostrado el grado de autonomía y de poder al que aspiraba (y que, por cierto, la política centralizadora de Luis XIV estaba lejos de otorgarle). El concepto rechazaba, al mismo tiempo, los desvaríos de una imaginación desbordada y la rigidez académica y exigía un cierto "buen sentido" -cuya definición era nebulosa- en la producción y recepción de las obras de arte ${ }^{5}$. La nobleza, así,

$4 \quad$ Es preciso notar que la dispersión del puritanismo en Inglaterra y el cierre de los teatros durante el protectorado de Cromwell habían demorado la recepción positiva de la obra de Shakespeare incluso en su propia tierra. Con la reapertura de los teatros luego de la Restauración, en 1660, el modelo clásico funcionó al interior de la isla como patrón para abordar críticamente las producciones dramatúrgicas isabelinas. Así, como ejemplo paradigmático, puede citarse el prefacio de Dryden a su adaptación de Troilus and Cressida, de 1675, en el que el autor explicaba (como lo harían muchos años más tarde los primeros traductores franceses) que era necesario purgar la obra shakespeareana de sus elementos más inquietantes: "He procedido a remover ese montón de basura bajo el cual muchos pensamientos excelentes permanecían totalmente enterrados" ("I undertook to remove that heap of rubbish under which many excellent thoughts lay wholly bury'd") (1717: 15). En un artículo reciente, Maximilien Novak (2014), si bien reconoce la influencia de ciertos críticos como Dryden, John Dennis y Charles Gildon en la valoración negativa de Shakespeare en la Inglaterra de la Restauración, sostiene que hacia 1715 el autor de Hamlet ya había adquirido el estatus de poeta nacional inglés gracias a una interpretación whiggish de la evolución literaria.

5 Según Dens, el bon goût "traduce los prejuicios estéticos de una clase aristocrática, la que frecuenta la Corte y los salones, y se encuentra entonces asociado con las cualidades con las que esa sociedad sueña, a saber la 
lograba revalidar estéticamente la lógica endogámica que la caracterizaba en sus concepciones políticas y sociológicas: el bon goût se poseía o no se poseía; las obras (y las personas) tenían o no tenían bon goût, pero resultaba imposible definir de manera precisa de qué se trataba ${ }^{6}$.

La combinación de bon goût y respeto por el ideal clásico de belleza confluyeron en el pensamiento de Voltaire sobre las artes ${ }^{7}$ y su consecuente crítica de la dramaturgia de Shakespeare, que se mantuvo constante a lo largo de toda su carrera intelectual, aunque se radicalizó a partir de la aparición de la traducción de sus obras completas (Naves, 1938: 335-336).

En 1768, Voltaire le escribía a Horace Walpole para responder a sus críticas contra la cultura francesa y a la acusación de ser el principal opositor europeo a la obra de Shakespeare. En esa carta, un Art poétique condensada (Finch \& Peers, 1920: 195), el philosophe se presentaba a sí mismo como el responsable de la introducción de los productos centrales de la cultura inglesa en la Francia de Luis XVI; dentro del corpus importado aparecía, centralmente, la figura de Newton, pero también la de Shakespeare: “Je suis le premier qui ai fait connaitre Shakespeare aux Français; j'en traduisis des passages, il y a quarante ans, ainsi que de Milton, de Waller, de Rochester, de Driden et de Pope. Je peux vous assurer qu'avant moi personne en France ne connaissait la poésie anglaise" (Voltaire, T.46 : 79).

La responsabilidad voltaireana en este proceso de apropiación fue tan reconocida que, luego del período del Terror revolucionario y en la búsqueda de culpables que pudieran explicar el devenir bárbaro de la nación, Julien-Louis Geoffroy, el más importante de los críticos teatrales durante la época napoleónica, apuntaba contra el autor de Candide, acusándolo de haber desnacionalizado el drama francés y, por su intermedio, viciado el carácter de los franceses y estimulado el apetito por el derramamiento de sangre y la violencia (Pemble, 2005: 12). El diagnóstico parcial de Geoffroy no tomaba en consideración el fuerte carácter crítico de las intervenciones voltaireanas, exacerbado hacia el final de su carrera. Así, si al comienzo de la carta a Walpole que evocamos el oficio de traductor e importador de tradiciones operaba, frente a su par inglés, como un principio legitimador de su rol como intelectual cosmopolita y tolerante de las diferencias culturales, inmediatamente después aparecían las objeciones a la poética shakespeariana.

El problema de Shakespeare, advertía Voltaire, no era su falta de genio, indiscutible para ese entonces, sino su carencia de goût, concepto asociado siempre, para el philosophe, con el de politesse (como demostraba, esencialmente, en sus obras historiográficas, v.g., Le Siècle de Louis XIV): haber nacido en una época bárbara, sin

delicadeza lo natural, el buen aire, el encanto. Así, el buen gusto no puede ser sino una etiqueta; es por eso que el P. Rapin declara que 'es en la práctica de las bienséances y en la idea que nos hacemos de ellas que consiste el buen gusto'. El buen gusto deviene en ese momento una exclusividad cultural de una clase social preocupada sobre todo por perpetuar su manera de apreciar una obra literaria" (Dens, 1975: 729).

6 El desafío que implicaba la obra de Shakespeare para el bon goût dieciochesco se corrobora no sólo en los escritos de Voltaire en los que nos detendremos a continuación sino cuando, en su campaña de reforma del drama francés y de rescate del bardo inglés, Victor Hugo afirma: "Voltaire lui a reproché son ivrognerie, et a bien fait. Pourquoi aussi, nous le répétons, pourquoi ce Shakespeare a-t-il un tel tempérament ? Il ne s'arrête pas, il ne se lasse pas, il est sans pitié pour les pauvres petits estomacs qui sont candidats à l'Académie. Cette gastrite, qu'on appelle “le bon goût", il ne l'a pas. Il est puissant » (Hugo, 1864: 286). (El destacado es nuestro.)

7 Sobre la importancia del clasicismo en la formación de la estética voltaireana, cfr. los capítulos III y V de la primera parte del insoslayable (y ya clásico) trabajo de Naves (1938). 
"l'élégance et la pureté" de la civilización que pregonaría Addison desde las páginas de The Spectator a comienzos del siglo XVIII, había conducido al bardo de Stratford a convertirse en el Lope de Vega o el Calderón de la Barca inglés: "C'est un belle nature mais bien sauvage; nulle régularité, nulle bienséance, nul art, de la bassesse avec de la grandeur, de la bouffonnerie avec du terrible : c'est le chaos de la tragédie dans lequel il y a cent traits de lumière" (Voltaire, T.46:80). Como puede observarse, era el incumplimiento de los principios clásicos (la ausencia de bienséances, la mezcla de lo bajo y lo elevado, de lo cómico y lo trágico) lo que impulsaba a Voltaire, auto-proclamado vocero de lo que "toute l'Europe éclairée pensé" (81), a objetar la producción shakespeariana. El recurso de Voltaire a los principios del clasicismo para criticar el teatro del autor de Hamlet se tornaba aún más evidente cuando recurría a Boileau para legitimar sus opiniones: su Art Poétique debía ser considerada, al menos, igual de importante que la de Horacio y "le sage Despréaux" no era otra cosa que "l'oracle du bon goût" (81).

Esta posición, aun relativamente moderada, se radicalizaría, como hemos adelantado, frente al prefacio de Letourneur a las obras completas de Shakespeare, en el que se denominaba al inglés como "dieu du théâtre" y que desencadenó una verdadera "guerra acerca de Shakespeare" (Jusserand, 1899: 329-397). En una serie de cartas escritas al Marqués d'Argental, Voltaire le solicitaba que compartiera su "colére" frente a las afirmaciones escandalosas del traductor, que se convertía en traidor no tanto por haber sido infiel con los originales sino por haberlo sido con la cultura francesa en su conjunto. El éxito de Letourneur entre la juventud parisina y los teatros franceses ocupados por obras inglesas eran, para el philosophe, el testimonio más evidente del ocaso de una cultura cuyo esplendor se había alcanzado en el reinado de Louis XIV y cuya decadencia le tocaba presenciar: "J'ai vu finir le règne de la raison et du goût. Je vais mourir en laissant la France barbare, mais heureusement vous vivez, et je me flatte que la reine ne laissera pas sa nouvelle patrie, dont elle fait le charme, en proie à des sauvages et à des monstres" (Voltaire, T.50 : 64).

El mismo diagnóstico se repetiría en la Lettre a l'Académie, aunque la argumentación resultaría en ese caso mucho más sutil y punzante. Voltaire demostraba, allí, que la operación crítica de Letourneur era hipócrita, porque al mismo tiempo que elogiaba el genio creativo inigualable de Shakespeare lo despojaba, al traducirlo, de muchas de las escenas que podían resultar escandalosas para el público francés. Refiriéndose, por ejemplo, a aquel famoso momento (borrado en la traducción) en que los chambelanes conversan, con un lenguaje bajo, sobre los efectos de la ebriedad en el organismo, inmediatamente después de que se consume el asesinato del rey Duncan por parte de Macbeth, Voltaire advertía: "Si de telles idées \& de telles expressions sont en effet cette belle nature qu'il faut adorer dans Shakespeare, son traducteur ne doit pas les dérober à notre culte. Si ce ne sont que les petites négligences d'un vrai génie, la fidélité exige qu'on les fasse connaître, ne fût-ce que pour consoler la France, en lui montrant qu'ailleurs il y a peut-être aussi des défauts" (Voltaire, T.30 : 354).

Las intervenciones del autor de Candide ou l'optimisme no estuvieron aisladas en el panorama de la segunda mitad del siglo XVIII sino que formaron parte de una atmósfera general en momentos en que la hegemonía cultural francesa comenzaba a ser disputada desde Inglaterra y Alemania: el pensamiento voltaireano contribuyó a dar forma a un modelo de identidad con el que las élites intelectuales y políticas se comprometieron mientras el poder francés y su lengua iban perdiendo territorio 
(Pemble, 2005: 14). La operación crítica de Letourneur resultaba tanto más peligrosa cuanto que representaba una amenaza contra el modelo cultural francés en su conjunto, un verdadero caballo de Troya literario mediante el cual el traductor se esforzaba por "immoler la France à l'Angleterre" en una obra paradójicamente dedicada al Rey de Francia y para la cual había obtenido suscripciones de la Reina y las princesas (Voltaire, T.30: 358). El philosophe procuraba demostrar que la adoración de genios aislados se oponía a la cultura francesa, en la cual la creatividad individual resultaba menos importante que la construcción nacional de un patrón de gusto relativamente homogeneizado, factor indicador del progreso de las costumbres y la civilité: "Vous voyez, messieurs, que dans les pays et dans les temps où les beaux-arts ont été le moins en honneur, il s'est pourtant trouvé des génies qui ont brillé au milieu des ténèbres de leur siècle. Ils tenaient de ce siècle où ils vécurent toute la fange dont ils étaient couverts ; ils ne devaient qu'à eux-mêmes l'éclat qu'ils répandirent sur cette fange" (Voltaire, T.30: 365). En última instancia, el supuesto rechazo de Shakespeare en todas las naciones civilizadas de Europa era la evidencia fundamental de que sus obras sólo placían en su Inglaterra natal y que, en ese sentido, respondían a un modelo literario incapaz de trascender las fronteras nacionales y erigirse como patrón de un buen gusto cosmopolita. Si Shakespeare resultaba peligroso para las pretensiones voltaireanas, si sus méritos habían terminado por sepultar el teatro inglés, era porque socavaba no solo los principios sobre los que se sostenía el drama francés sino la posibilidad de construir un homo gustibus universalis, una verdadera República de las Letras con estándares definidos (y, preferentemente, definidos desde Francia).

Esta triple alianza contra Shakespeare (bon goût, Voltaire, neoclasicismo; factores que, como hemos visto, se encuentran sólidamente imbricados) puede percibirse condensada, por ejemplo, en el prólogo con el que el editor, inspirado por las Lettres anglaises del philosophe, introducía La mort de César de Voltaire:

Shakespeare, père de la tragédie anglaise, est aussi le père de la barbarie qui y règne. Son génie sublime, sans culture et sans goût, a fait un chaos du théâtre qu'il a créé. Ses pièces sont des monstres dans lesquels il y a des parties qui sont des chefs-d'œuvre de la nature. Sa tragédie intitulé La Mort de César commence par son triomphe au Capitole et finit par la mort de Brutus et de Cassius a la bataille de Philippes. On assassine César sur le théâtre. On voit des sénateurs bouffonner avec la lie du peuple. C'est un mélange de ce que la tragédie a de plus terrible et de ce que la farce a de plus bas (cit. en Dubedout, 1906: 308).

Por culpa de estos prejuicios, las primeras puestas teatrales de Shakespeare en Paris, llevadas a cabo por Jean Marie Ducis a partir de 1760, pueden considerarse tardías herederas de un género que había florecido en el Renacimiento, que había servido para codificar el gusto neoclásico y que, de acuerdo con el magistral estudio de Roger Zuber, ya había desaparecido hacia 1653 (Zuber, 1968): las "belles infidéles"8, aquellas obras que constituían, más que traducciones fieles al original,

8 La expresión se le atribuye al lexicógrafo Gilles Ménage, quien la acuñó luego de leer las traducciones de Luciano de Samosata a cargo de Perrot d'Ablancourt: "Elles me rappellent une femme que j'ai beaucoup aimé à Tours, qui était belle mais aussi infidèle" (cit. en Zuber: 195-6). El propio Voltaire, en el catálogo de escritores que acompañaba su Le siècle de Louis XIV, reconocía que Perrot d'Ablancourt era "traducteur élégant et dont on appela chaque traduction la belle infidèle" (Voltaire, XIV: 115). 
adaptaciones a lo que el autor consideraba que era o debía ser el gusto de la época (como vimos que ocurriría más tarde con las traducciones de Letourneur). En Macbeth, por ejemplo, la escena del banquete en que el protagonista ve el espíritu de Banquo después de haber ordenado su asesinato estaba borrada, porque representar momentos en que se estuviera comiendo no cumplía con los códigos trágicos; las brujas no aparecían en escena, aunque sí aparecían mencionadas y también se omitía la escena cómica del portero (Drake, 2012) ${ }^{9}$. Diderot, con buen sentido, prefería los originales de Shakespeare a las puestas de Ducis (Cru, 1919: 439).

¿Cuáles eran las razones profundas por las que el original despertaba en nuestro autor más interés que la copia? Intentaremos, en lo que sigue, responder a este interrogante siguiendo una cronología invertida. Comenzaremos por mostrar rápidamente algunas de las particularidades más modernas de su pensamiento maduro, condensado en el Salon de 1767 y en la Paradoxe sur le comédien; luego nos detendremos brevemente en los dos trabajos fundacionales de su teoría teatral (Conversations sur le fils naturel y De la poésie dramatique, de 1757 y 1758) para exponer el que consideramos el núcleo central allí desarrollado. Retrocederemos entonces hacia un texto aún más temprano (la Lettre sur les sourds et muets, de 1751). Si el método elegido resulta adecuado, gracias a este recorrido à rebours podremos demostrar nuestra hipótesis: que la obra de Shakespeare, lejos de ser de importancia lateral, ocupa un lugar central en toda la producción de Diderot, no sólo en cuanto a lo actoral, sino en la postulación combativa, desde fines de la década del 50, de una nueva poética para el arte dramático. La organización de la lógica teatral bajo un paradigma a la vez pictórico y pantomímico es la principal operación que realiza Diderot y encuentra su punto de condensación, avant la lettre, en un momento particular de la obra shakesperiana, que se convierte así en un exemplum estético del modo en que el drama debe funcionar cuando el decoro y un lenguaje excesivamente codificado se han convertido desde hace tiempo en obstáculos para cumplir con la función de emocionar de manera verdaderamente profunda al público.

\section{Lo sublime, lo pictórico y la absorción en la teoría dramática de Diderot}

Mine eye hath played the painter and hath steeled/ Thy beauty's form in table of my heart; / My body is the frame wherein 'tis held, / And perspective that is best painter's art. / For through the painter must you see his skill.

Shakespeare, Sonnet 24, 1-5.

A pesar de las posturas que hemos venido reseñando, la obra de Shakespeare estuvo lejos de ser unánimemente rechazada en el siglo ilustrado. El trabajo de Letourneur fue bien recibido, incluso, por algunos críticos ortodoxos. El mismo año en que Voltaire enviaba su carta a la Academia, el Anné Littéraire de Fréron, polemista católico, saludaba la monumental traducción como una manera de combatir la

$9 \quad$ En el Avertissement, Ducis aclara: "Me he dedicado desde el principio a hacer desaparecer la impresión siempre revulsiva del horror, que ciertamente hubiera hecho fracasar mi obra, y he tratado a continuación de conducir el alma de mi espectador hasta los últimos grados del terror trágico mezclándolo con arte con lo que podría hacerlo soportable" (Ducis, 1827: 121). 
esterilidad que afectaba al escenario francés, y algo similar ocurría con el tradicional Journal des savants (Pemble, 2005: 22-23). Antes de la traducción, además, se habían alcanzado picos de entusiasmo gracias a las sucesivas visitas a Paris del actor inglés David Garrick (Jusserand, 1899: 288), discípulo del Dr. Johnson y co-administrador del célebre teatro Drury Lane, cuyo modo apasionado de representar escenas de diversas obras de Shakespeare había puesto en cuestión la excesivamente codificada actuación francesa, despertando una admiración profunda en ciertos círculos intelectuales y, en particular, en Denis Diderot, quien había compartido reuniones con el actor en 1764 y 1765. Las reflexiones en torno a la actuación de Garrick se repiten a lo largo del corpus diderotiano. Así, por ejemplo, en la célebre respuesta a la carta que Mme. Roccoboni le enviara para criticar su Le père de famille, el editor de la Encyclopédie encontraba en las pantomimas del inglés un antídoto contra las convenciones neoclásicas que convertían el cuerpo del comediante en un maniquí, al fijar, entre otras cuestiones, la máxima altura a la que se podían colocar las manos, el grado de separación de los brazos del torso y el modo correcto de inclinarse (Diderot, T.VII: 402).

Las representaciones de Garrick y las opiniones que despertaron entre los críticos franceses fueron, de hecho, el punto de partida de la históricamente más influyente de las reflexiones diderotianas sobre el teatro: la Paradoxe sur le comédien, escrita entre 1773 y 1777 pero publicada póstumamente recién en $1830^{10}$. En un diálogo cuyo objetivo principal es demostrar que, contra lo que se suele pensar, el mejor actor no es aquel que se deja colonizar por las emociones de su personaje sino el que lo estudia fríamente, Diderot comienza señalando las diferencias insalvables entre los modos de representar a los dos más grandes dramaturgos de Inglaterra y Francia, Shakespeare y Racine, diferencias derivadas de la incompatibilidad en la manera de escribir tragedias a uno y otro lado del Canal de la Mancha (Diderot, T.VIII: 364). El philosophe sugiere que no se debería comparar al bardo inglés ni con 'l'Apollon du Belvédère, ni au Gladiateur, ni à l'Antinoüs, ni à l'Hercule de Glycon" sino con "Christophe de Notre-Dame, colosse informe, grossièrement sculpté, mais entre les jambes duquel nous passerions tous sans que notre front touchât à ses parties honteuses" (Diderot, T.VIII : 384).

Junto a la influencia que tuvo Garrick para alcanzar esta valoración, no es aventurado sugerir que la fascinación de Diderot por la obra de Shakespeare se debió, en buena medida, a la recepción y asimilación del influyente tratado de Edmund Burke de 1757 (A Philosophical Enquiry into the Origin of Our Ideas of the Sublime and Beautiful $)^{11}$ que, a partir del concepto de lo sublime, le permitió a nuestro autor la configuración asistemática de una estética ya no basada en el orden y la mesura, como pregonaba el clasicismo, sino en el caos, la confusión, la mezcla, el exceso. La "nueva estética" se evidencia con la mayor claridad en el Salón de 1767 y puede caracterizarse como una oposición tajante a las reglas académicas y al concepto de bon goût.

En la famosa "Promenade Vernet", un "paseo" ficcional por los paisajes que Vernet -uno de sus pintores favoritos- propone en sus pinturas, Diderot discute con su

10 La Paradoxe retoma las ideas ya formuladas por Diderot en su artículo Observations sur une brochure intitulée "Garrick où les acteurs anglaises", publicado en la Correspondance Littéraire de Friedrich Melchior Grimm en 1770.

11 Sobre la relación entre Diderot y Burke, cfr. el artículo de May (1960). 
cicerone, quien le pregunta si el espíritu filosófico es favorable o desfavorable a la poesía. Contesta:

Plus de verve chez les peuples barbares que chez les peuples policés; plus de verve chez les Hébreux que chez les Grecs ; plus de verve chez les Grecs que chez les Romains ; plus de verve chez les Romains que chez les Italiens et les Français ; plus de verve chez les Anglais que chez ces derniers. Partout décadence de la verve et de la poésie, à mesure que l'esprit philosophique a fait des progrès on cesse de cultiver ce qu'on méprise. Platon chasse les poètes de sa cité. L'esprit philosophique veut des comparaisons plus resserrées, plus strictes, plus rigoureuses [...]. Tous les préjugés civils et religieux se dissipent; et il est incroyable combien l'incrédulité ôte de ressources à la poésie. Les mœurs se policent, les usages barbares, poétiques et pittoresques cessent et il est usages barbares, poétiques et pittoresques cessent et il est incroyable le mal que cette monotone politesse fait à la poésie (Diderot, T.XI: 131).

Es difícil exagerar la radicalidad de este pasaje en relación con los estratos semánticos que se habían ido acumulando en el concepto de gusto desde la época de Luis XIV y, muy fuertemente, durante la primera mitad del siglo XVIII (desde el tratado de Dubos -1719- hasta el de Batteux -1747): la politesse ${ }^{12}$, un savoir-vivre que cumple un rol esencial en la génesis del concepto clásico de bon goût (Fumaroli, 2013; Dens, 1980), ya no es necesaria para el desarrollo de la poesía sino que lo obstaculiza. La producción artística se despega de su carácter racional y se concibe la posibilidad de que entre filosofía y poesía no haya una relación de complementariedad sino una de oposición.

Esta intuición se ve reforzada en el artículo "Génie" de la Encyclopédie, publicado el mismo año que el tratado de Burke, escrito por Saint Lambert pero, según argumenta Dieckmann (1941), posiblemente retocado y con certeza influido por Diderot:

Le goût est souvent séparé du génie. Le génie est un pur don de la nature; ce qu'il produit est l'ouvrage d'un moment; le goût est l'ouvrage de l'étude \& du tems; il tient à la connoissance d'une multitude de regles ou établies ou supposées; il fait produire des beautés qui ne sont que de convention. Pour qu'une chose soit belle selon les regles du goût, il faut qu'elle soit élégante, finie, travaillée sans le parô̂tre: pour être de génie il faut quelquefois qu'elle soit négligée; qu'elle ait l'air irrégulier, escarpé, sauvage. Le sublime \& le génie brillent dans Shakespear comme des éclairs dans une longue nuit, \& Racine est toûjours beau: Homere est plein de génie, \& Virgile d'élégance ${ }^{13}$.

Así como poesía y razón, gusto y genio, los dos conceptos fundamentales en torno a los cuales se organiza el pensamiento estético de la segunda mitad del siglo XVIII, se repelen.

La importancia de Shakespeare en ambos pasajes es evidente: en el segundo la referencia es directa; en el primero se lo evoca al reconocerle a Inglaterra un carác-

12 Los conceptos de "civilité" y "politesse", como explicó convincentemente Elias (2009: 117), expresan "la autoconsciencia de la clase superior europea frente a otras clases consideradas como más simples o más primitivas". Cfr., al respecto, el gran estudio de France (1992).

13 La Encyclopédie se encuentra completa en internet gracias a un fabuloso proyecto de la Universidad de Chicago (https://encyclopedie.uchicago.edu/). Respetamos la ortografía. 
ter más poético que el que impera en Francia. Si bien es cierto que es a partir de los Salones que se torna posible pensar retrospectivamente en una relación del pensamiento de Diderot con el romanticismo, es necesario advertir que nuestro autor se manifestaba desde sus primeros escritos inconforme con la estética imperante en su época, cuyos principios habían redundado, según sostenía, en una proliferación de convenciones que había destruido toda la capacidad emotiva del drama francés. Ya en la primera página de sus tempranos Pensées philosophiques (1746), Diderot se posicionaba en contra del extremo racionalismo que conducía a una producción artística anquilosada y muda:

On déclame sans fin contre les passions ; on leur impute toutes les peines de l'homme, et l'on oublie qu'elles sont aussi la source de tous ses plaisirs. C'est dans sa constitution un élément dont on ne peut dire ni trop de bien ni trop de mal. Mais ce qui me donne de l'humeur, c'est qu'on ne les regarde jamais que du mauvais côté. On croirait faire injure à la raison, si l'on disait un mot en faveur de ses rivales ; cependant il n'y a que les passions, et les grandes passions, qui puissent élever l'âme aux grandes choses. Sans elles, plus de sublime, soit dans les mœurs, soit dans les ouvrages ; les beaux-arts retournent en enfance, et la vertu devient minutieuse (Diderot, T.I: 2).

Estas luminosas intuiciones tempranas, contemporáneas con las primeras traducciones de Shakespeare al francés (las diez obras traducidas por Pierre Antoine de La Place, belles infidèles, son de 1745), son retomadas en las Conversations sur le fils naturel (1757) y De la poésie dramatique (1758), los dos textos donde Diderot define una estética teatral propia intentando consolidar en Francia, en la débil tradición de Paul Landois, el así llamado "drame bourgeois".

Acaso la mayor operación teórico-conceptual de estos trabajos sea la formulación de una teoría pictórica y pantomímica del drama, en la que los "coûps de théâtre" (giros inesperados de la trama) son reemplazados por "tableaux dans la scéne" (que se perciben como si fueran pinturas) y en la que, por lo tanto, el discurso pasa a ocupar un segundo plano con respecto a la acción y la imagen ${ }^{14}$.

En su argumentación en favor de una des-discursivización del lenguaje teatral y una restitución de su dimensión visual, pantomímica, Diderot se muestra como sintetizador de una triple herencia. Por un lado, de una buena parte de la tradición occidental, que le otorga a la vista el escalafón más elevado en una hipotética pirámide de los sentidos (Markiewicz, 1987; Serres, 2008); por el otro, de la Querelle du coloris del último cuarto del siglo XVII (Lichtenstein, 1993), que logra posicionar a la pintura, en tanto lenguaje no dependiente de signos arbitrarios, como un medio privilegiado y alternativo de acceso a la verdad; por último, de la desconfianza en la capacidad expresiva del lenguaje verbal que comienza a manifestarse en la época clásica a partir de la lógica de Port-Royal (Foucault, 1997; Sennett, 1978).

En contraste con lo que piensa Rousseau en el Essai sur l'origine des langues (escrito entre 1755 y 1761 , en los años de creciente tensión con el grupo de los enciclopedistas), que relaciona el lenguaje gestual con la argumentación y el verbal con

14 De acuerdo a la brillante interpretación sociológica de Peter Szondi (1980), los tableaux resultan más efectivos para que el nuevo público burgués, cuya vida es más previsible y ordenada que la del inestable e intrigante mundo cortesano, pueda sentir empatía con los personajes y recibir el impacto moralizante que Diderot pretende. 
la emoción, y en consonancia con Batteux ${ }^{15}$, el autor de las Conversations sostiene que nunca son los discursos los que afectan más profundamente el alma en los espectáculos. Para restituirle al drama el pathos de la vieja tragedia griega es necesario desarrollar el lenguaje pantomímico, definido como "expresión de un discurso por gestos" (Ida, 1999: 35), puesto que, según asegura, no son palabras lo que el público espera llevarse del teatro sino impresiones (Diderot, T.VII: 314): "on se rapelle facilement les événements, mais non les discours" (Diderot, T.VII: 316), "ce qui émeut toujours, ce sont des cris, des mots inarticulés, des voix rompues, quelques monosyllabes qui s'échappent par intervalles, je ne sais quel murmure dans la gorge, entre les dents" (Diderot, T.VII, 105) ${ }^{16}$. Por lo tanto, "la pantomime est une portion du drame ; [...] l'auteur s'en doit occuper sérieusement; $[\ldots]$ si elle ne lui est pas familière et présente, il ne saura ni commencer, ni conduire, ni terminer sa scène avec quelque vérité; et $[\ldots]$ le geste doit s'écrire souvent à la place du discours" (Diderot, T.VII : 378).

La teoría pictórica, pantomímica y gestual -que, reiteramos, destaca la capacidad del mensaje visual, no verbal, de penetrar más fuertemente y de conmover de manera más profunda el alma- es la pieza central de la poética teatral diderotiana, que se formula de manera acabada a fines de la década del ' 50 y reaparece y se complejiza en diversos escritos sobre otras artes de allí en adelante. Y sin embargo, dista de ser un descubrimiento maduro en sus reflexiones artísticas; por el contrario, se encuentra en germen en la Lettre sur les sourds et muets, y sólo volcándonos hacia ella es posible justificar el lugar central que, de acuerdo a la hipótesis que adelantamos, ocupa Shakespeare en las reflexiones de nuestro autor.

Concebida como una suerte de respuesta al influyente tratado de Batteux (y a menudo leída como precursora de la teoría de la fisión de las artes de Lessing), la Lettre tiene como uno de sus objetivos centrales demostrar que la lengua francesa es más adecuada para hablar el lenguaje de la razón que el de las pasiones: según sostiene Robert Cru, en una sociedad demasiado polie, "era un instrumento poético más débil que el griego, el latín, el italiano o el inglés" (Cru, 1919: 434). Advierte Diderot:

Nous avons gagné $[\ldots]$ de la netteté, de la clarté, de la précision, qualités essentielles au discours ; [...] nous y avons perdu de la chaleur, de l'éloquence et de l'énergie. J'ajouterais volontiers que la marche didactique et réglée à laquelle notre langue est assujettie, la rend plus propre aux sciences; et que, par les tours et les inversions que le grec, le latin, l'italien, l'anglais se permettent, ces langues sont plus avantageuses pour les lettres (Diderot, T.I: 371 ).

Orden, claridad, precisión: las características del lenguaje francés, inapelables desde un punto de vista racional, son débiles cuando se trata de conmover. Ya no

15 En Les beaux arts réduits à un même príncipe, Batteux postula que el hombre tiene tres medios para expresar sus ideas y sentimientos: la palabra, el tono de la voz y el gesto. "La palabra nos instruye, nos convence, es el órgano de la razón; pero el tono y el gesto son los del corazón: ellos nos conmueven, nos ganan, nos persuaden" (Batteux, 1989: 231).

16 Se muestra, en este punto, como heredero de la teoría del lenguaje de Condillac (1746), quien le atribuye al lenguaje primitivo, oponiéndose a nominalistas como Smith y Herder, una capacidad poética y emotiva muy fuerte, al punto que hay autores que hablan de una "teatralización de las necesidades humanas" en la que el significante es el movimiento de la voz y el cuerpo y el significado es la emoción (Pécharman, 1999; Coskl, 2006). 
estamos en la "edad de la elocuencia" (por evocar el precioso libro de Marc Fumaroli), sino en otro mundo, uno cuyo estar out of joint (por evocar, ahora, la frase hamletiana), exige nuevos desafíos creativos y representativos ${ }^{17}$. Si las palabras perdieron su capacidad emotiva y si, por cierto, no resulta razonable pedirle a la nación entera que cambie su lengua por el inglés, es necesario recurrir a otro lenguaje, uno cuyas características pueden adivinarse retrocediendo sobre el mismo texto que estamos analizando, hacia un momento en el que Diderot reflexiona sobre la posibilidad de traducir el lenguaje gestual de los sordomudos a un lenguaje verbal. Tal cosa sería en principio posible, dice, excepto en ciertos casos. Y es aquí, en medio de una discusión de índole técnica, si se quiere, donde encontramos el pasaje que, creemos, puede funcionar como clave de bóveda para todo el pensamiento estético diderotiano que se desarrollará en los siguientes años y eclosionará en el Salón de 1767. Dice Diderot:

Il y a des gestes sublimes que toute l'éloquence oratoire ne rendra jamais. Tel est celui de Macbeth dans la tragédie de Shakespeare. La somnambule Macbeth s'avance en silence (acte $V$, scène i), et les yeux fermés, sur la scène, imitant l'action d'une personne qui se lave les mains, comme si les siennes eussent encore été teintes du sang de son roi qu'elle avait égorgé il y avait plus de vingt ans. Je ne sais rien de si pathétique en discours que le silence et le mouvement des mains de cette femme. Quelle image du remords! (Diderot, T.I: 354-5).

El gesto triunfa sobre el discurso: el arrepentimiento, la culpa, la angustia, la locura de Lady Macbeth luego del asesinato de Duncan no pueden ser representados mediante ninguna elocuencia oratoria; el método adecuado no es en todo caso el de la exposición sino el de la demostración, pero no la demostración matemática del silogismo ni la demostración hipócrita que alientan las convenciones sociales de una nobleza que pretende distinguirse sino aquella que define la primera acepción del diccionario de Trévoux de 1742: "La acción por la cual se muestra o indica alguna cosa. Mostratio, indicatio" (Starobinski, 1995: 172). Se trata de poner frente a la vista, de "faire tableau", de convertir en cuadros las escenas en lugar de reproducir palabras, palabras y palabras que, como ya lo había intuido Hamlet, estaban dejando de referir de manera transparente al mundo.

Este momento culminante de la obra de Shakespeare resulta fundamental para Diderot porque, desde el comienzo de sus reflexiones, lo obliga a atender a tres aspectos que serán piezas inamovibles de sus ulteriores desarrollos teóricos. Por un lado, en su ponderación de lo gestual, la escena de Macbeth le restituye al teatro su dimensión visual, pre-lingüística, pictórica; por el otro, funciona como paradigma de una estética de la absorción de acuerdo a la cual tanto los actores en su actuación como los escritores en su producción deben lograr olvidar la figura del espectador y concebir su práctica de manera autónoma, único modo, paradójicamente, de captar verdaderamente la atención del público (Fried, 1988); por último, el autor inglés se convierte en el paradigma avant la lettre de la estética de lo sublime que, si se percibe ya en De la poésie dramatique, aparecerá con plenitud a partir de los Salones.

17 En este sentido, la denuncia de Diderot de la esencial limitación del lenguaje verbal y su crítica a la retórica lo convierten en uno de los ilustrados que prepara el terreno para el advenimiento del Romanticismo (Fumaroli, 1995). 
No queremos decir, con esto, que pueda hablarse de una sólida e ininterrumpida continuidad en la estética diderotiana, tan dispersa y a menudo auto-contradictoria a pesar de los esfuerzos de algunos críticos y comentaristas por alcanzar una síntesis, pero sí que existe la posibilidad de sugerir un puente entre sus escritos más tempranos y sus reflexiones tardías. Ese puente, si tenemos razón, se sostiene, en buena medida, en la apabullante maestría dramatúrgica, no necesariamente lingüística, de William Shakespeare.

\section{Referencias bibliográficas}

Batteux, Ch., (1989) Les Beaux-Arts réduits à un même principe. Paris, Aux Amateurs de livres. Besterman, Th., (1967) Voltaire on Shakespeare. Géneve, Droz.

Coskl, Ch., (2006) "Emotion and poetry in Condillac's theory of language and mind", in The French Review. Vol. 80, nº 1, pp. 157-170.

Cru, L., (1919) Diderot as a disciple of English thought. New York, Columbia University Press.

Diderot, D., (1875-7) Oeuvres complètes (ed. Assezat). Paris, Garniér Freres. T. I, IV y V.

Dens, J.P., (1975) "La notion de 'bon goût' au XVII" siècle : historique et définition", in Revue belge de philologie et d'histoire. Vol. 53, nº 3, pp. 726-729.

Dens, J.P., (1981) L'honnête homme et la critique du goût. Lexington, French forum Pub.

Dieckmann, H., (1941) "Diderot's conception of genius", in Journal of the history of ideas. Vol. 2, no 2, pp. 151-182.

Drake, A., (2012) "Jean-François Ducis: Re-Creating Shakespeare for an Eighteenth-Century Audience", in Selected papers of the Ohio Valley Shakespeare Conference. Ohio State University [En línea]. Disponible en: http://blogs.uakron.edu/ovsc/issues/currentissue-2/jean-francois-ducis-re-creating-shakespeare-for-an-eighteenth-century-audience/ [Último acceso el 4 de abril de 2014].

Dryden, J., (1717) Troilus and Cressida or Truth found too late. London.

Dubedout, E.J., (1906) “Shakespeare et Voltaire; 'Othello' et 'Zaïre”, in Modern Philology. Vol. 3, n 3 , pp. 305-316.

Ducis, J.F., (1827) Euvres de J.F. Ducis. Tome second. Paris, Aimé André.

Elias, N., (2009) El proceso de la civilización. Investigaciones sociogenéticas y psicogenéticas. México, FCE.

Finch, M.B. \& E.A. Peers, (1920) “Walpole's Relations with Voltaire”, in Modern Philology. Vol. $18, n^{\circ} 4$, pp. 189-200.

Foucault, M., (1997) Las palabras y las cosas. Buenos Aires, Siglo XXI. Trad.: Elsa Frost.

France, P., (1992) "Polish, Police, Polis", in Politeness and its discontents. Problems in french classical culture. Cambridge, Cambridge University Press.

Fried, M., (1988) Absorption and theatricality: Painting and beholder in the age of Diderot. Chicago, University of Chicago Press.

Fumaroli, M., (1995). "De l'Age de l'éloquence à l'Age de la conversation: la conversion de la rhétorique humaniste dans la France du XVII siècle", in Bray, B. \& Ch. Strosetzki, Art de la Lettre, Art de la Conversation à l'époque classique en France. Paris, Klincksieck.

Fumaroli, M., (2013) Le sablier renversé. Des anciens aux modernes. Paris, Gallimard.

Hugo, V., (1867) William Shakespeare. Paris, A. Lacroix, Verboeckhoven et Cie, éditeurs. 
Ida, H., (1999). "La pantomime selon Diderot. Le geste et la démonstration morale", in Recherches sur Diderot et sur l'Encyclopédie. № 27, pp. 25-42.

Jusserand, J.J., (1899) Shakespeare in France under the ancient regime. London, Fisher Unwin.

Lichtenstein, J., (1993) The eloquence of color. Rhetoric and painting in the French classical age. Berkeley-Los Angeles-Oxford, University of California Press.

Markiewicz, H., (1987) "Ut Pictura Poesis... A History of the Topos and the Problem", in New Literary History. Vol. 18, n 3, On Poetry, pp. 535-558.

May, G., (1960) "Diderot and Burke. A study in aesthetic affinity", in PMLA. Vol. 75, n 5, pp. 527-539.

Naves, R., (1938) Le goût de Voltaire. Paris, Garnier Frères.

Novak, M., (2014) "The politics of Shakespeare's criticism in the Restoration and early Eighteenth century", in ELH, Vol. 81, no 1, pp. 115-142.

Pécharman, M., (1999) "Signification et langage dans l'Essai de Condillac", in Revue de Métaphysique et de morale. $\mathrm{N}^{\mathrm{o}} 1$, pp. 53-80.

Pemble, J., (2005) Shakespeare goes to Paris. How the bard conquered France. London and New York: Hambledon and London.

Rousseau, J.J., (1984) Ensayo sobre el origen de las lenguas. México D.F., FCE. Trad.: Adolfo Castañón.

Sennett, R., (2011) El declive del hombre público. Barcelona, Anagrama. Trad.: Gerardo di Masso.

Serres, M., (1985) Les Cinq Sens. Paris, Éditions Grasset et Fasquelle.

Szondi, P., (1980) "Tableau and Coup de Théâtre: On the Social Psychology of Diderot's Bourgeois Tragedy", in New Literary History. Vol. 11, n 2, pp. 323-343. Trad.: Harvey Mendelsohn.

Voltaire, (1877-1885) Euvres complètes de Voltaire. Paris, Garnier.

Weinbrot, H., (1993) "Enlightenment Canon Wars: Anglo-French Views of Literary Greatness", in ELH. Vol. 60, n 1, pp. 79-100

Zuber, R., (1968) Les « Belles Infidèles » et la formation du goût classique. Paris, Armand Colin. 